\title{
"A novel hybrid MCDM model for financial performance evaluation in Iran's food industry"
}

\begin{tabular}{ll} 
AUTHORS & $\begin{array}{l}\text { Moslem Alimohammadlou } \\
\text { Abbas Bonyani }\end{array}$ \\
\hline ARTICLE INFO & $\begin{array}{l}\text { Moslem Alimohammadlou and Abbas Bonyani (2017). A novel hybrid MCDM } \\
\text { model for financial performance evaluation in Iran's food industry. Accounting } \\
\text { and Financial Control, 1(2), 38-45. doi:10.21511/afc.01(2).2017.05 }\end{array}$ \\
\hline DOI & http://dx.doi.org/10.21511/afc.01(2).2017.05 \\
\hline RELEASED ON & Thursday, 28 December 2017 \\
\hline RECEIVED ON & Monday, 06 November 2017 \\
\hline ACCEPTED ON & Wednesday, 27 December 2017 \\
\hline LICENSE & $\begin{array}{l}\text { (co) EY-No } \\
\text { Inis work is licensed under a Creative Commons Attribution-NonCommercial } 4.0\end{array}$ \\
\hline JOURNAL & "Accounting and Financial Control" \\
\hline ISSN PRINT & $2543-5485$ \\
\hline ISSN ONLINE & $2544-1450$ \\
\hline PUBLISHER & LLC “Consulting Publishing Company “Business Perspectives" \\
\hline FOUNDER & Sp. z 0.0. Kozmenko Science Publishing \\
\hline
\end{tabular}

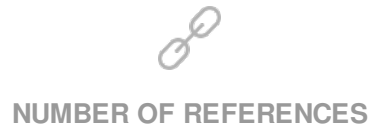

19

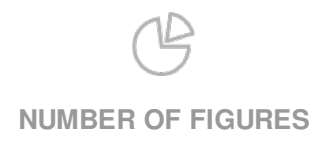

4

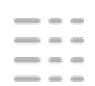

NUMBER OF TABLES

4

(C) The author(s) 2023. This publication is an open access article. 


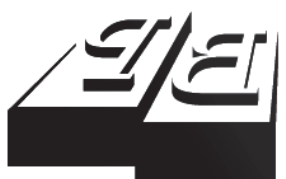

BUSINESS PERSPECTIVES

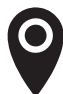

LLC "CPC "Business Perspectives" Hryhorii Skovoroda lane, 10, Sumy, 40022, Ukraine

www.businessperspectives.org

Received on: $6^{\text {th }}$ of November, 2017 Accepted on: $27^{\text {th }}$ of December, 2017

(C) Moslem Alimohammadlou, Abbas Bonyani, 2017

Moslem Alimohammadlou, Department of Industrial Management, Faculty of Economic, Management and Social Science, Shiraz University, Shiraz, Iran.

Abbas Bonyani, Department of Industrial Management, Faculty of Management and Accounting, Allameh Tabataba'i University, Tehran, Iran.

\section{A NOVEL HYBRID MCDM MODEL FOR FINANCIAL PERFORMANCE EVALUATION IN IRAN'S FOOD INDUSTRY}

\begin{abstract}
The use of financial ratios as the necessary information is considered as one of the noticeable issues for researchers to apply quantitative models for evaluating the performance of institutions. The reason for introducing these new approaches is that the financial ratios cannot individually provide a correct and adequate understanding of an institution's performance. This study sought to propose a model for evaluating and ranking 14 companies which are considered as the largest companies in Iran's food industry according to the recent report of Industrial Management institute (IMI). To accomplish this, an integrated model composed of Best-Worst method and PROMETHEE II was used. Results of data analysis revealed that in final evaluation, some companies such as NOOSH MAZAN Co., PYAZR AI Co. and PEGAH ESF Co. had higher positions compared to the others.
\end{abstract}

Keywords financial performance, Best-Worst method, PROMETHEE II

\section{JEL Classification G30, O12}

\section{INTRODUCTION}

Financial performance of a company, being one of the major characteristics, defines competitiveness, potentials of the business, economic interests of the company's management and reliability of present or future contractors. Therefore, financial performance analysis and identification of their weaknesses and strengths using financial performance indicators has its contribution to the management, shareholders, the public (customers of the bank), the regulator (the government), the financial sector, and the economy as a whole. Performance evaluation of a company is usually related to how well a company can use it assets, shareholder equity and liability, revenue and expenses. Financial ratio analysis is one of the best tools of performance evaluation of any company. Performance evaluation provides opportunity for management to find out which corporate activity ensures more revenue than cost (Neely, 2004). Performance evaluation helps investors, especially private equity investors to measure the added value of their non-financial services (Becsky-Nagy \& Fazekas, 2014).

The measurement and the evaluation of firm performance has gained great importance under today's current competitive environment. Therefore, in order to survive in the evolving and changing world market, it is essential for firms to strengthen and to keep their financial structure under control. An efficient financial analysis is essential to ensure the effective implementation of financial policies. In general terms, financial analysis is defined as an investigation of the relation between financial accounts and development of those accounts over time allow- 
ing managers to determine whether the firm has sufficient financial independence and the ability to make predictions for the future. Multi-Criteria Decision Making analysis is used to provide a solution to the problem where there are multiple and incompatible set of decision criteria. The purpose of this study is to propose a model that can evaluate and rank 14 companies, which are considered as the largest companies in Iran's food industry according to the recent report of Industrial Management institute (IMI). In this regard, an integrated model composed of Best-Worst method and PROMETHEE II was used.

\section{LITERATURE REVIEW}

The use of financial ratios to evaluate the performance of institutions has a long history. In recent years, a noticeable increase in application of these ratios can be seen. Fasanghari and Montazer (2010) have used the fussy expert system to choose the best stock in Tehran Stock Exchange. GU and Yue (2011) have evaluated the financial performance of manufacturing companies listed in Istanbul Stock Exchange using the fuzzy decision-making techniques. Yalcin et al. (2012) proposed a pattern for evaluating the hierarchical performance based on the main criteria for evaluating traditional and modern financial performance. They obtained the weight of criteria using the fuzzy AHP and then, used the VIKOR and TOPSIS method to rank the manufacturing companies listed in Istanbul Stock Exchange in each industry in 2007. Magazine (2011) annually evaluates and ranks the top 500 American companies (53 different industrial and commercial activities) given the income and profitability index. Value Line institute annually evaluates and ranks 1700 different companies in all industries around world with regard to the price performance index. Standard \& Poor's institute annually evaluates all the industries of the World with regard to the Securities risk index.

Fuentes and Lillo (2015) have investigated the efficiency growth of 30 Spanish tax offices between 2004 and 2006. In addition, they have divided the productivity into two components including efficiency and the impact of technology changes. Results of their study based on Malmquist index showed that the productivity is increased in both periods given the development in technology and resource management. Technology development consideration and also appropriate resource management in the first and second periods, respectively, are the reasons for increment of productivity. Although the productivity of most offices was increased due to the technological changes, on the overage, improvement in management was more effective in increasing the productivity of these offices. Due to the impact of pollution and climate change on communities and their economies, Sueyoshi and Goto (2015) have addressed this issue. Their empirical study showed that the main changes of efficiency is due to the management innovation rather than change in the level of consumable resources. In other words, oil companies have improved their environmental performance using the eco-technology in order to reduce the carbon dioxide emission during the observed annual period. Dong et al. (2015) have analyzed the china's air and space industry aimed at examining the airspace performance in China and comparing the difference in productivity between private aerospace companies and public one. Researchers found that returns to scale and technical level of the industry have increased over the period under review, and this increase was mainly due to the growth of public companies. However, despite the productivity enhancement given the scale, the total productivity of sampled was reduced and it was due to the decrease in productivity indices of leading companies in China's air and space industry. Generally, the operational productivity of the industry was still relatively low. Comparing private companies and public ones in terms of scale, they found that performance of the private companies is very lower than that of public ones. However, private companies were more efficient in terms of operating productivity, indicating an imbalance in development of the air and space industry in China.

Abbas et al. (2015) have used Malmquist Index to investigate and compare the performance of Islamic and conventional banks in Pakistan during the period of 2005-2009. Results showed that the productivity of Islamic banks has been reduced in 2007, but between 2008 and 2009, the productivity of banks was increased. Islamic banks experienced a higher productivity growth between 2005 and 2006, but in the next years, their growth were lower than their traditional counterparts. Results of their study in- 


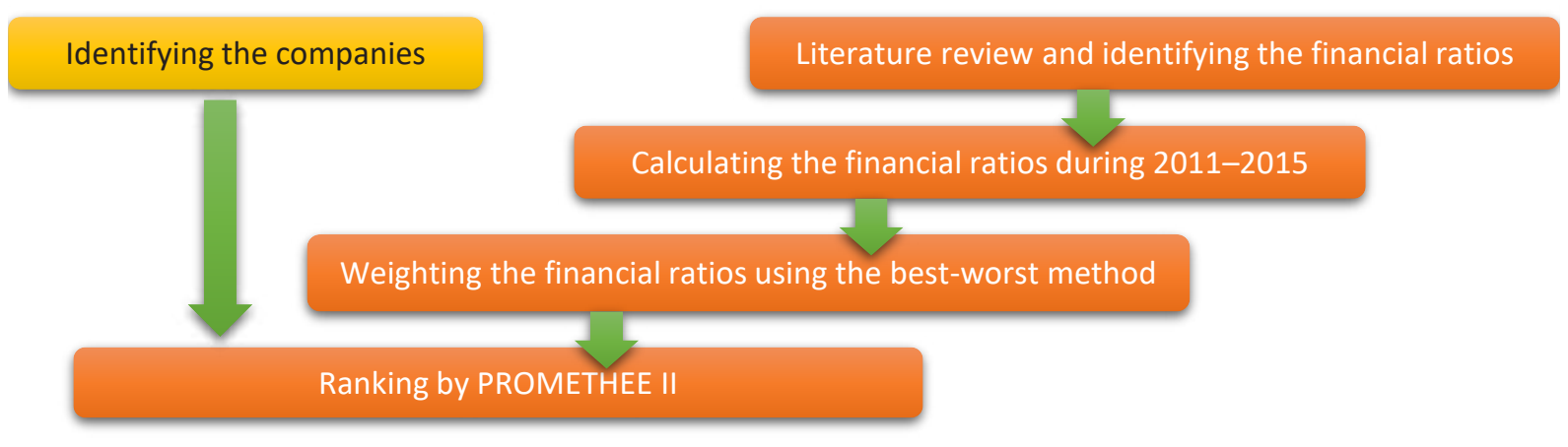

Figure 1. Research stages

dicate a decrease in the total productivity of Islamic banks and their counterparts after 2007 due to a sharp decrease in productivity that resulted from the reduction in GDP, two-digit inflation, and high interest rate for controlling the inflation, trade deficit and high government loan. Finally, during this period, results showed a statistically significant difference between the performance of Islamic banks and conventional banks between 2006 and 2009.

Mousa (2015) has investigated the banking efficiency of Bahrain Exchange between 2010 and 2013 using the financial ratios and DEA technique. His work uses six financial ratios to evaluate four attributes of banks. According to the results, only two banks were perfectly efficient during the period of 2010-2013. The advantage of applying the DEA is that this model can determine the required values to decrease inputs and increase outputs in order to increase the productivity of banks with the productivity less than one.

As it is clear from the review of the related work, evaluating the financial performance of companies in order to decision-making for investment had been a topic of interest to researchers and they have used different methods for this topic. The similarity of this research with other researches in this field can be seen in the use of DEA window analysis and multi-criteria decision-making techniques. But, the difference between this research and previous work can be seen in the simultaneous use of the two approaches, including, dynamic analysis (combination of DEA Window Analysis and Malmquist Index) and cross-sectional analysis (combination of PROMETHEE II and Best-Worst Method) and comparing both approaches that in conducted studies were not used simultaneously in form of a proposed method.

\section{METHODS}

This study was an applied method in terms of subjective and also was descriptive in terms of data collection and in quantitative form. Statistical population of this study is consisted of 14 companies which are considered as the largest companies in Iran's food industry according to the recent report of Industrial Management institute (IMI). In this study, with regard to the research stages in Fig. 1, after identifying the companies and reviewing the previous work, financial ratios are identified and calculated for the period 2011-2015. Then companies are ranked by combining the Best-Worst method and PROMETHEE II method.

\subsection{Best-Worst method}

In an MCDM problem, a number of alternatives are evaluated with respect to a number of criteria in order to select the best alternative(s). According to BWM, the best (e.g. most desirable, most important) and the worst (e.g. least desirable, least important) criteria are identified first by the decision-maker. Pairwise comparisons are then conducted between each of these two criteria (best and worst) and the other criteria. A maximin problem is then formulated and solved to determine the weights of different criteria. The weights of the alternatives with respect to different criteria are obtained using the same process. The salient features of the proposed method, compared to the existing MCDM methods, are: (1) it requires less comparison data; (2) it leads to more consistent comparisons, which means that it produces more reliable results (Rezaei, 2015). 


\subsection{The steps of BWM:}

Step 1. Determine a set of decision criteria. In this step, we consider the criteria $\left\{C_{1}, C_{2}, \ldots, C_{n}\right\}$ that should be used to arrive at a decision.

Step 2. Determine the best (e.g. most desirable, most important) and the worst (e.g. least desirable, least important) criteria4. In this step, the decision-maker identifies the best and the worst criteria in general. No comparison is made at this stage.

Step 3. Determine the preference of the best criterion over all the other criteria using a number between 1 and 9. The resulting Best-to-Others vector would be:

$$
A_{B}=\left(a_{B 1}, a_{B 2}, \ldots, a_{B n}\right),
$$

where $a_{B j}$ indicates the preference of the best criterion $\mathrm{B}$ over criterion $\mathrm{j}$. It is clear that $a_{B B}=1$

Step 4. Determine the preference of all the criteria over the worst criterion using a number between 1 and 9. The resulting Others-to-Worst vector would be:

$$
A_{W}=\left(a_{1 W}, a_{2 W}, \ldots, a_{n W}\right)^{T},
$$

where $a_{j W}$ indicates the preference of the criterion $j$ over the worst criterion $W$. It is clear that $a_{W W}=1$

Step 5. Find the optimal weights $\left(w_{1}^{*}, w_{2}^{*}, \ldots, w_{n}^{*}\right)$, he optimal weight for each criterion is the one where, for each pair $w_{B} / w_{j}$ and $w_{j} / w_{W}$, it should have $w_{B} / w_{j}=a_{B j}$ and $w_{j} / w_{W}=a_{j W}$. To satisfy these conditions for all $\mathrm{j}$, it should determine a solution where the maximum absolute gaps $\left|w_{B} / w_{j}-a_{B j}\right|$ and $\left|w_{j} / w_{W}-a_{j W}\right|$ for all $j$, are minimized. Considering the non-negativity and sum condition for the weights, the following problem is resulted:

$$
\min \max _{j}\left\{\left|\frac{w_{B}}{w_{j}}-a_{B j}\right|,\left|\frac{w_{j}}{w_{w}}-a_{j w}\right|\right\}
$$

s.t.

$$
\sum_{j} w_{j}=1, \quad w_{j} \geq 0, \text { for all } j
$$

Eq. (3) can be transferred to the following problem: $\min \xi$

s.t.

$$
\begin{aligned}
& \left|\frac{w_{B}}{w_{j}}-a_{B j}\right| \leq \xi, \text { for all } j \\
& \left|\frac{w_{j}}{w_{w}}-a_{j w}\right| \leq \xi, \text { for all } j \\
& \sum_{j} w_{j}=1, w_{j} \geq 0, \text { for all } j
\end{aligned}
$$

Of course, the linear model of the function above is represented as follows (Rezaei, 2016). In this paper, the weights of the criteria are obtained through the linear model.

$\min \xi$

s.t.

$$
\begin{aligned}
& \left|w_{B}-a_{B j} w_{j}\right| \leq \xi, \text { for all } j \\
& \left|w_{j}-a_{j w} w_{w}\right| \leq \xi, \text { for all } j, \\
& \sum_{j} w_{j}=1, \\
& w_{j} \geq 0, \text { for all } j
\end{aligned}
$$

We then calculate the consistency ratio, using $\xi$ and the corresponding consistency index (see Table 1), as follows:

Consistency Ratio $=\frac{\xi}{\text { Consistency Index }}$

\subsection{PROMETHEE II method}

PROMETHEE is a comprehensive MCDM method that was developed by Brans and Vincke (1985) and further extended by Brans et al. (1986). PROMETHEE is also a rather simple ranking method in concept and in practice when compared with the other MCDM methods (Greco et al., 2005). Different versions of the PROMETHEE have been developed including PROMETHEE II, which is the most frequently applied version because it enables a decision maker (DM) to find a full ranked vector of alternatives (i.e., complete ranking). The PROMETHEE II method involves 
Table 1. Consistency index (Cl) table

\begin{tabular}{c|c|c|c|c|c|c|c|c|c|c}
\hline $\mathbf{a}_{\mathrm{BW}}$ & $\mathbf{1}$ & $\mathbf{2}$ & $\mathbf{3}$ & $\mathbf{4}$ & $\mathbf{5}$ & $\mathbf{6}$ & $\mathbf{7}$ & $\mathbf{8}$ & $\mathbf{9}$ \\
\hline Consistency index & 0.00 & 0.44 & 1.00 & 1.63 & 2.30 & 3.00 & 3.73 & 4.47 & 5.23 \\
\hline
\end{tabular}

six steps (Behzadian et al., 2010; Podvezko \& Podviezko, 2010):

Step 1. Construction of an evaluation matrix: the basic data must be prepared in the evaluation matrix in which the performance of each alternative with respect to each criterion is provided.

Step 2. Determination of performance differences: the performance difference between each pair of alternatives with respect to each criterion is calculated as follows:

$$
d_{j}(a . b)=g_{j}(a)-g_{j}(b),
$$

where $g_{j}(a)$ and $g_{j}(b)$ show the performance of alternatives $a$ and $b$, respectively, with regard to criterion $j$, and $d_{j}(a . b)$ denotes the difference between these performances.

Step 3. Constructing the preference functions. Six types of preference functions that are commonly used in practice have been proposed by Brans et al. (1986): (1) usual criterion, (2) U-shape criterion, (3) V-shape criterion, (4) level criterion, (5) V-shape with indifference criterion and (6) Gaussian criterion.

Step 4. Calculation of aggregated preference indices: for each pair of alternatives, an aggregated preference index is calculated as follows:

$$
\pi(a . b)=\sum_{j=1}^{k} w_{j} P_{j}(a . b)
$$

where $\pi(a . b)$ denotes the overall preference of a over $b$, and wj is the weight associated with the jth criterion.

Step 5. Calculation of outranking flows: for each alternative $a$ when compared with (n-1) other alternatives in $A$, a positive and negative outranking flow is calculated as follows:

$$
\begin{aligned}
& \phi^{+}(a)=\frac{1}{n-1} \sum_{x \in A} \pi(a, x) \\
& \phi^{-}(a)=\frac{1}{n-1} \sum_{x \in A} \pi(x, a)
\end{aligned}
$$

Step 6. Calculation of net outranking flows: the net outranking flow of alternative $a$ can be calculated as follows:

$$
\phi(a)=\phi^{+}(a)-\phi^{-}(a)
$$

Using these net outranking flows, PROMETHEE II can provide a complete ranking of the alternatives from best to worst (Macharis et al., 2004).

\section{RESULTS}

In this part, the financial performance of companies was evaluated using the combination of multi-criteria decision-making techniques including Best-Worst method and PROMETHEE II technique that the Best-Worst method was used to calculate weights of indices and the PROMETHEE II method was used to final ranking of companies.

\subsection{Weighting the financial ratios using the best-worst method}

To determine the weights of the criteria, according to the steps of the BWM, after the criteria were decided, the best and worst criterion were found. Next, the preference of the best criterion over all the other criteria and also preference of all the criteria over the worst criterion are specified by numbers 1 to 9 . Following that, based on the priority vector obtained from pairwise comparisons, the model was framed according to Eq. (5) and was solved in Lingo software. The model's outputs were considered to be the weights of the criteria assigned by each expert. Finally, the average of the weights obtained for each expert was calculated; these averaged values represented the ultimate weights for each criterion.

\subsection{Decision Matrix}

After calculating the weights of financial ratios, the mean of these ratios is calculated for the 5 -year period (2011-2015) and the decision matrix is obtained in accordance with Table 3. 
Table 2. Calculating the weight of financial ratios

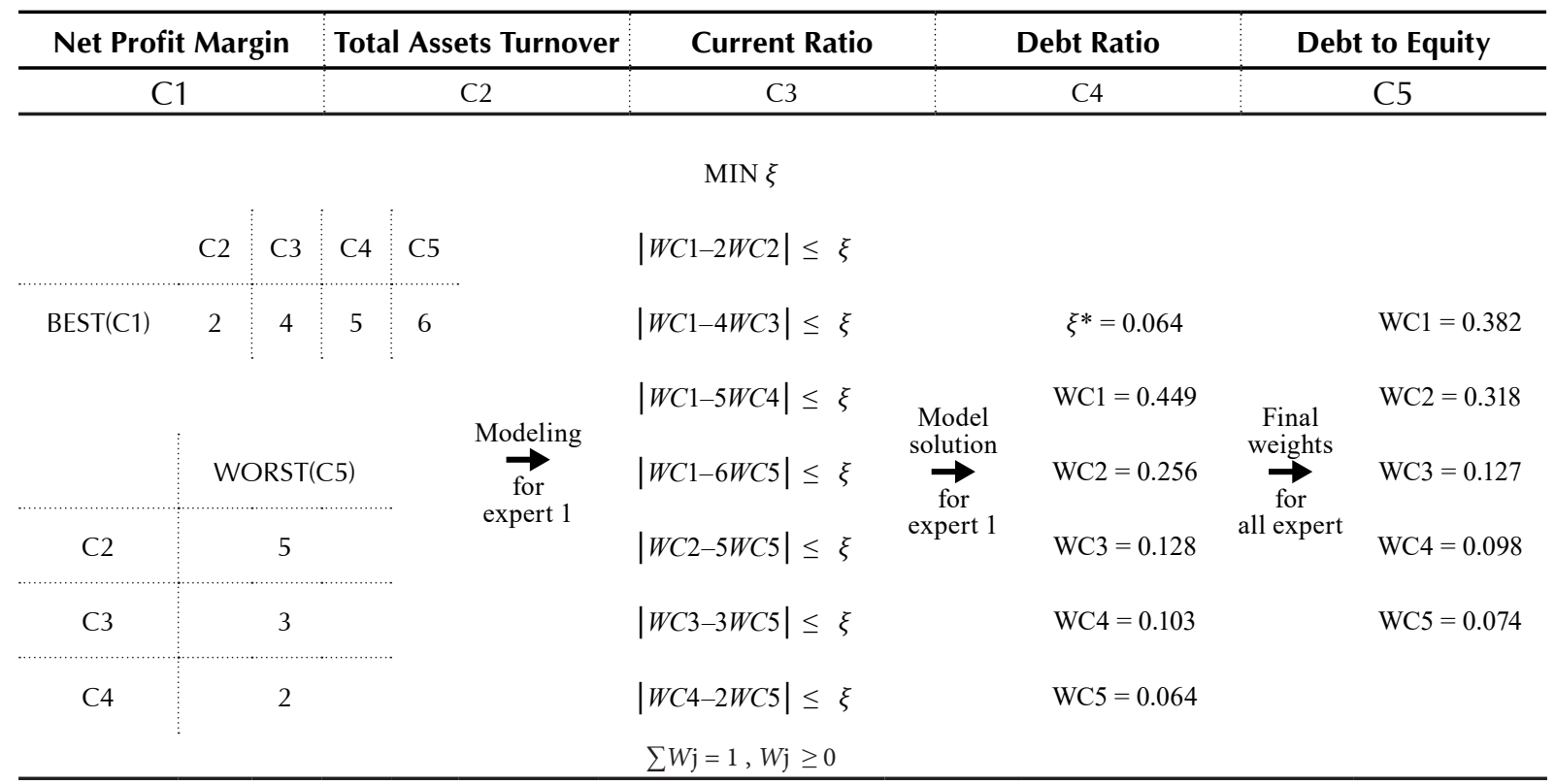

\subsection{Ranking by PROMETHEE II}

Final ranking of alternatives was calculated using the PROMETHEE II technique (Table 4), and then, relative position of alternatives with respect to the criteria were extracted (Figure 3). Table 4 shows the pure flow of preference. The flow resulted from the balance between positive and negative ranking flow. Higher pure flow indicates the preferred alternative. Figure 2 shows the preference of alternatives in form of a network, in which each action is represented as a node and preferences are represented by arrows.

Table 3. Decision Matrix

\begin{tabular}{|c|c|c|c|c|c|c|}
\hline \multirow{7}{*}{ Company } & \multirow{2}{*}{ Indicator } & $\begin{array}{l}\text { Net Profit } \\
\text { Margin }\end{array}$ & $\begin{array}{l}\text { Total Assets } \\
\text { Turnover }\end{array}$ & $\begin{array}{c}\text { Current } \\
\text { Ratio }\end{array}$ & $\begin{array}{l}\text { Debt } \\
\text { Ratio }\end{array}$ & $\begin{array}{c}\text { Debt to } \\
\text { Equity }\end{array}$ \\
\hline & & $\mathrm{C} 1$ & $\mathrm{C} 2$ & $\mathrm{C} 3$ & $\mathrm{C} 4$ & C5 \\
\hline & Weight & 0.382 & 0.318 & 0.127 & 0.098 & 0.074 \\
\hline & Min/Max & $\operatorname{Max}$ & $\operatorname{Max}$ & Max & Min & Min \\
\hline & Type & V & IV & V & V & IV \\
\hline & Indifference & 5 & 0.5 & 0.5 & 15 & 10 \\
\hline & preference & 10 & 1 & 1 & 30 & 20 \\
\hline KALBER Co. & $\mathrm{A} 1$ & 6.427 & 1.068 & 1.237 & 45.827 & 0.942 \\
\hline GORJI Co. & A2 & 0.526 & 1.755 & 0.882 & 85.467 & 12.255 \\
\hline MINOO Co. & A3 & 13.112 & 0.833 & 0.852 & 62.370 & 1.789 \\
\hline WAPD Co. & A4 & -4.358 & 0.739 & 0.437 & 95.360 & 46.826 \\
\hline PYAZR AI Co. & A5 & 12.803 & 1.183 & 2.754 & 48.415 & 0.988 \\
\hline PAK Dairy Co. & A6 & 1.439 & 1.985 & 0.855 & 84.497 & 6.162 \\
\hline PEGAH KHO Co. & A7 & 4.368 & 2.701 & 1.266 & 65.044 & 2.102 \\
\hline IR BEHNOUSH Co. & A8 & 6.817 & 1.040 & 0.678 & 89.137 & 10.709 \\
\hline PEGAH ESF Co. & A9 & 5.241 & 2.713 & 1.059 & 66.612 & 2.065 \\
\hline DASHTE MORGHAB CO. & A10 & -3.535 & 0.753 & 0.913 & 92.270 & 35.711 \\
\hline SHAHDIRAN Co. & A11 & -3.602 & 0.537 & 1.594 & 50.427 & 1.033 \\
\hline SALEMIN Co. & $\mathrm{A} 12$ & 4.690 & 1.068 & 1.140 & 57.531 & 1.692 \\
\hline NOOSH MAZAN Co. & A13 & 28.155 & 0.655 & 2.378 & 39.688 & 0.707 \\
\hline MAHRAM CO. & A14 & 2.508 & 1.383 & 1.049 & 90.096 & 9.354 \\
\hline
\end{tabular}


Figure 4 shows the pure flow of each alternative re- way, the balance between positive and negative slices lated to each criteria, in which the Positive (upward) is equal to the Phi score. Actions are ranked from left slices correspond to good features while negative to right according to the PROMETHEE II Complete (downward) slices correspond to weaknesses. This Ranking.

Table 4. PROMETHEE Flow

\begin{tabular}{|c|c|c|c|}
\hline & $\varnothing$ & $\varnothing+$ & $\boldsymbol{\varnothing}-$ \\
\hline A13 & 0.452 & 0.574 & 0.122 \\
\hline A5 & 0.345 & 0.448 & 0.103 \\
\hline A9 & 0.289 & 0.382 & 0.093 \\
\hline A7 & 0.277 & 0.377 & 0.099 \\
\hline A3 & 0.146 & 0.302 & 0.156 \\
\hline $\mathrm{A} 1$ & 0.038 & 0.178 & 0.140 \\
\hline A6 & 0.017 & 0.200 & 0.183 \\
\hline A12 & -0.027 & 0.135 & 0.162 \\
\hline A2 & -0.047 & 0.171 & 0.218 \\
\hline A8 & -0.080 & 0.122 & 0.202 \\
\hline A14 & -0.125 & 0.098 & 0.223 \\
\hline A11 & -0.291 & 0.097 & 0.388 \\
\hline A10 & -0.467 & 0.003 & 0.470 \\
\hline A4 & -0.527 & 0.000 & 0.527 \\
\hline
\end{tabular}

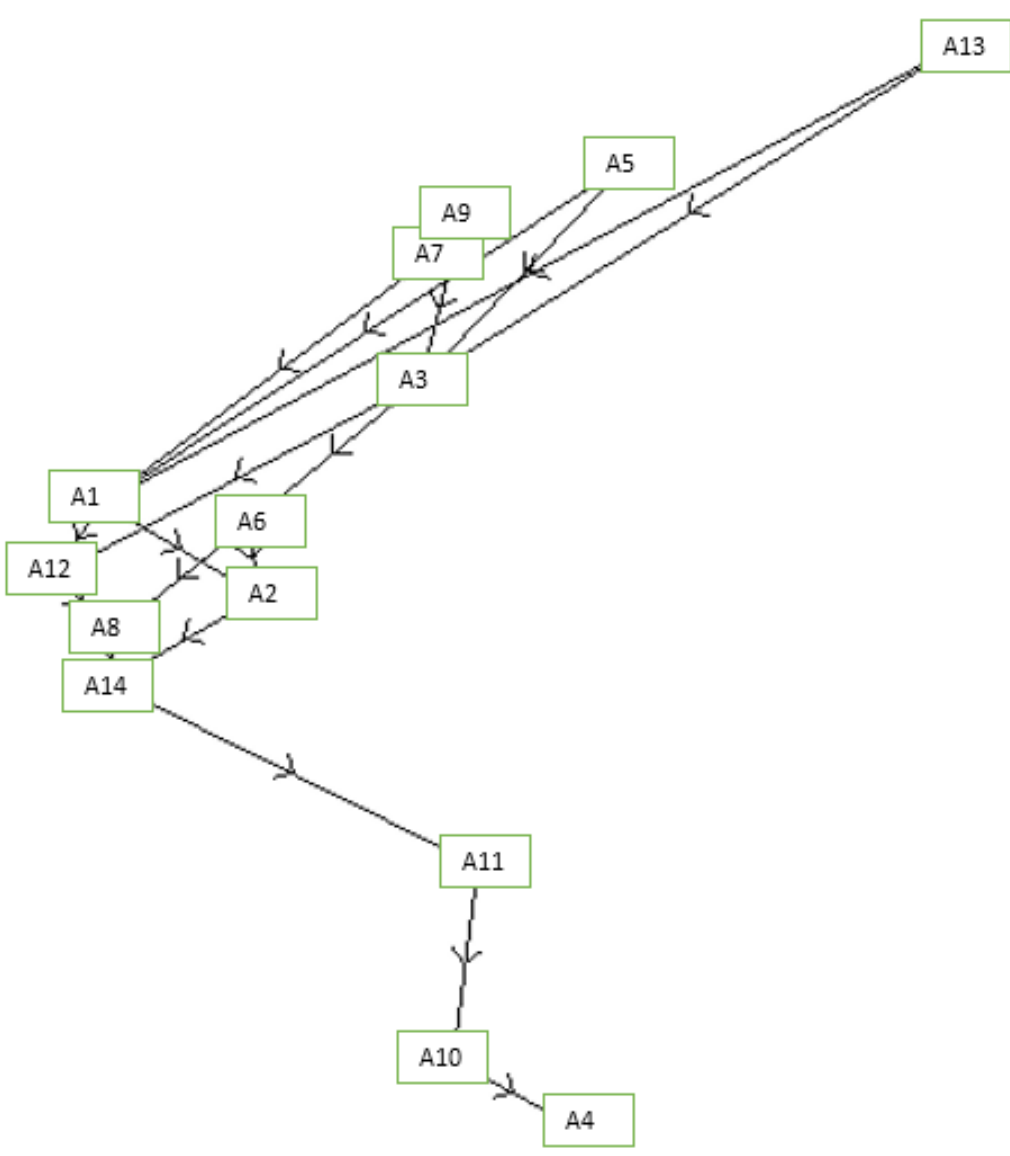

Figure 2. PROMETHEE Network

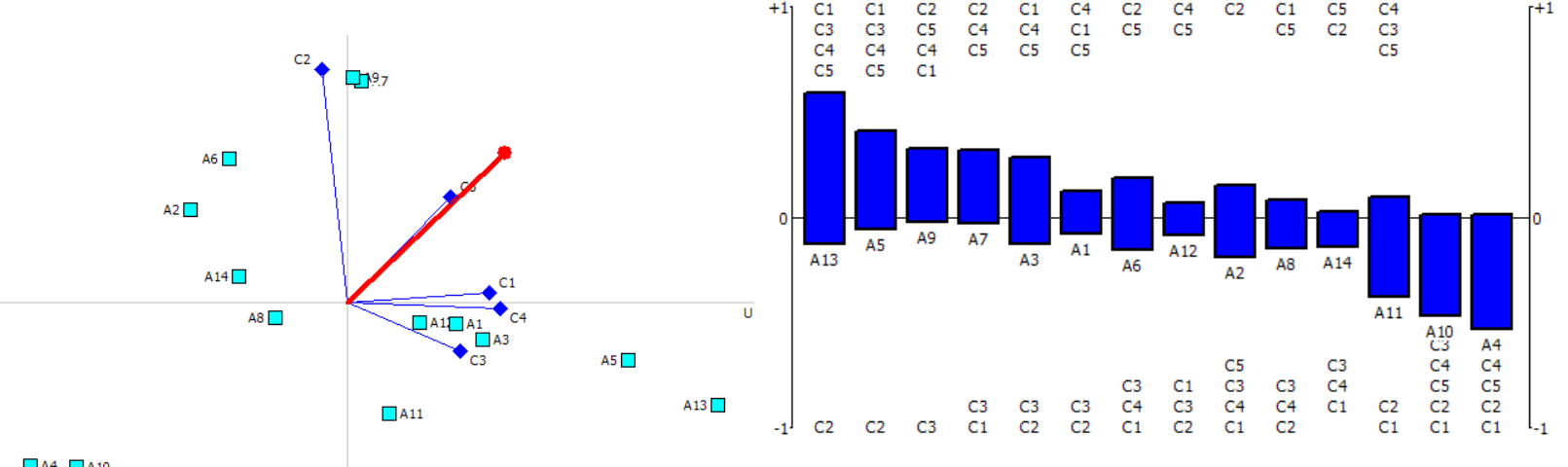

$\square$ A4 $\square$ A10

Figure 3. PROMETHEE GAIA

Figure 4. PROMETHEE Rainbow 


\section{DISCUSSION AND CONCLUSIONS}

The main focus of this study was that the financial ratios cannot individually provide a proper understanding of the performance of an institution, and given that it is not easy to comment about the financial performance of business units, this information can be misleading for investors and shareholders of companies. Therefore, applying the quantitative patterns of evaluating the financial performance in recent years has been considered by the researchers. In this study, the researches sought a way to find an appropriate pattern for evaluating the financial performance of companies, and to this end, a combination the latest and most appropriate methods has been provided. Results of data analysis revealed that in final evaluation some companies such as NOOSH MAZAN Co., PYAZR AI Co. and PEGAH ESF Co. had higher positions compared to the others.

\section{REFERENCES}

1. Abbas, Muhammad, Rayan, S. Hammad, Elshahat, Mohamed Fathy \& Toseef, Azid (2015). Efficiency, Productivity and Islamic Banks: An Application of Dea and Malmquist Index. Humanomics: The International Journal of Systems and Ethics, 31(1), 118-131.

2. Becsky-Nagy, P., Fazekas, B. (2014). Returns of private equity: comparative analyses of the returns of venture capital and buyout funds in Europe and in the US Annals of the University of Oradea. Economic Science, 2(2), 820- 827.

3. Behzadian, Majid, Reza Baradaran Kazemzadeh, Amir Albadvi, \& Mohammad, Aghdasi (2010). Promethee: A Comprehensive Literature Review on Methodologies and Applications. European journal of Operational research, 200(1), 198-215.

4. Brans, J. P., \& Vincke, Ph. (1985). Note-a Preference Ranking Organisation Method: (the Promethee Method for Multiple Criteria Decision-Making). Management science, 31(6), 647-656.

5. Brans, J. P., Vincke, Ph., \& Mareschal B. (1986). How to Select and How to Rank Projects: The Promethee Method. European journal of operational research, 24(2), 228-238.

6. Dong, Peiwu, Kai Qiao, \& Mei Yang (2015). Operational Efficiency across the Chinese Aerospace Industry: A Dea and
Malmquist Analysis. Chinese

Management Studies,

9(4), 553-570.

7. Fasanghari, M., \& Montazer, G. A. (2010). Design and Implementation of Fuzzy Expert System for Tehran Stock Exchange Portfolio Recommendation. Expert Systems with Applications, 37(9), 6138-6147.

8. Fuentes, R., \& Lillo-Bañuls, A. (2015). Smoothed Bootstrap Malmquist Index Based on Dea Model to Compute Productivity of Tax Offices. Expert Systems with Applications, 42(5), 2442-2450.

9. Greco, S., Figueira, J., \& Ehrgott, M. (2005). Multiple Criteria Decision Analysis. Springer's International series.

10. Gu, Hongmei, \& Jiahui, Yue (2011). The Relationship between Bank Efficiency and Stock Returns: Evidence from Chinese Listed Banks. World Journal of Social Sciences, 1(4), 95-106.

11. Macharis, C., Springael, J., De Brucker, K., \& Verbeke, A. (2004). Promethee and Ahp: The Design of Operational Synergies in Multicriteria Analysis.: Strengthening Promethee with Ideas of Ahp. European Journal of Operational Research, 153(2), 307-317.

12. Magazine Fortune (2011). Annual Ranking of Americas Largest Corporations.

13. Mousa, G. A. (2015). Financial Ratios Versus Data Envelopment
Analysis: The Efficiency Assessment of Banking Sector in Bahrain Bourse. International Journal of Business and Statistical Analysis, 2(2), 75-84.

14. Neely, A. (Ed.) (2004). Business performance measurement: Theory and practice. Cambridge: University Press.

15. Podvezko, V., \& Podviezko, A. (2010). Dependence of Multi-Criteria Evaluation Result on Choice of Preference Functions and Their Parameters. Technological and Economic Development of Economy, 16(1), 143-158.

16. Rezaei, J. (2015). Best-Worst Multi-Criteria Decision-Making Method. Omega, 53, 49-57.

17. Rezaei, J. (2016). Best-Worst Multi-Criteria Decision-Making Method: Some Properties and a Linear Model. Omega, 64, 126-130.

18. Sueyoshi, T., \& Goto, M. (2015). Dea Environmental Assessment in Time Horizon: Radial Approach for Malmquist Index Measurement on Petroleum Companies. Energy Economics, 51, 329-345.

19. Yalcin, N., Bayrakdaroglu, A., \& Kahraman, C. (2012). Application of Fuzzy Multi-Criteria Decision Making Methods for Financial Performance Evaluation of Turkish Manufacturing Industries. Expert Systems with Applications, 39(1), 350-364 